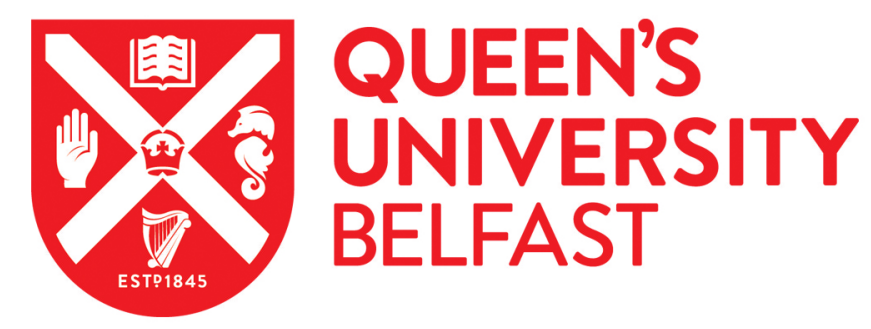

\title{
In lakes but not in minds: stakeholder knowledge of invasive species in prairie lakes
}

\author{
Nanayakkara, L., Jurdi-Hage, R., Leavitt, P. R., \& Wissel, B. (2018). In lakes but not in minds: stakeholder \\ knowledge of invasive species in prairie lakes. Biological Invasions, 20(3), 633-652. \\ https://doi.org/10.1007/s10530-017-1564-4, https://doi.org/10.1007/s10530-017-1564-4
}

\section{Published in:}

Biological Invasions

\section{Document Version:}

Peer reviewed version

Queen's University Belfast - Research Portal:

Link to publication record in Queen's University Belfast Research Portal

\section{Publisher rights}

(C) 2017 Springer International Publishing AG.

This work is made available online in accordance with the publisher's policies. Please refer to any applicable terms of use of the publisher.

\section{General rights}

Copyright for the publications made accessible via the Queen's University Belfast Research Portal is retained by the author(s) and / or other copyright owners and it is a condition of accessing these publications that users recognise and abide by the legal requirements associated with these rights.

Take down policy

The Research Portal is Queen's institutional repository that provides access to Queen's research output. Every effort has been made to ensure that content in the Research Portal does not infringe any person's rights, or applicable UK laws. If you discover content in the Research Portal that you believe breaches copyright or violates any law, please contact openaccess@qub.ac.uk. 

prairie lakes

${ }^{1}$ University of Regina, 3737 Wascana Parkway, Regina SK, S4S 0A2, Canada

*Corresponding author: email (lushanin@gmail.com), telephone (306-529 9766)

\section{Acknowledgements}

12 We thank Ron Hlasny from the SK Ministry of Environment for his assistance in this study.

13 Fishing rods offered as prizes were generously donated by Cabela's. Funding for this study was

14 provided by a Natural Sciences and Engineering Research Council of Canada (NSERC) grant to

15 B. Wissel, and Teaching Assistance and Research scholarships from the University of Regina

16 and the Government of Saskatchewan to L. Nanayakkara. 


\section{Abstract}

22 Humans are key vectors in the spread and establishment of aquatic invasive species (AIS), and

23 human behavior can exacerbate or help prevent further spread of non-native species. Therefore,

24 stakeholders' knowledge is critical to preventing establishment of AIS. However, stakeholders'

25 AIS knowledge in prairie lakes remains poorly understood. We used a survey questionnaire in

26 Saskatchewan, Canada, to assess the state of AIS knowledge, identify predictors of knowledge,

27 and optimize management strategies. Statistical analyses of the responses of 440 participants

28 indicated a generally low level of AIS knowledge, suggesting low communication success.

29 Respondents were generally more aware of non-native fishes than plants. Of concern was the

30 observation of substantial knowledge gaps regarding non-native mussels and important

31 preventative behaviors that may have devastating ecological, social, and economic consequences

32 if left unaddressed. Better understanding of AIS issues was significantly associated with several

33 trans-situational (age, sex and education), situational (recreational purpose and using multiple

34 lakes), and lake-related knowledge (awareness of eutrophication) predictors. Exploitation of

35 these predictors is recommended to improve effectiveness of outreach and communication

36 efforts. Specifically, we propose that management strategies focus on improving

37 communications by streamlining outreach messages, targeting low-knowledge groups (e.g.,

38 swimmers, cabin owners), and expanding education campaigns.

39 Keywords: AIS knowledge; prairie lakes; survey research; knowledge predictors; outreach;

40 communications strategy. 
Invasive species are a critical threat to freshwater ecosystems in North America (Dextrase

44 and Mandrak 2006). Their spread is tightly linked to human activities (e.g., economic

45 development, disturbance, travel, trade), which can result in accidental or deliberate

46 introductions of non-native species to new habitats (Drake et al. 2014; Edwards et al. 2016;

47 Gates et al. 2009; Touza et al. 2014). Therefore, human behavior, including knowledge of

48 environmental issues, should be a key component of efforts regulating the spread of invasive

49 species (Bremner and Park 2007; Jetter and Paine 2004; Shackleton and Shackleton 2016).

50 Support for invasive species management increases with the public`s understanding of invasive

51 species' biology and mechanisms of prevention or control. But uneven education of the public

52 regarding invasive species can also lead to divisive debates on the desirability of, control and

53 eradication efforts (Bremner and Park 2007). In particular, lack of community consensus for

54 eradication of invasive species can cause management efforts to fail ( García-Llorente et al.

55 2008; Moon et al. 2015). Support for management efforts can markedly increase when focus

56 group discussions with stakeholders relay the rationale and methodology of invasive species

57 eradication (Bremner and Park 2007). Findings suggest that stakeholders' knowledge about

58 invasive species can influence their prevention, spread, and control, both through direct public

59 action and support for management strategies (Ansong and Pickering 2015; Carlson and

60 Vondracek 2014; Ford-Thompson et al. 2015; Sharp et al. 2011).

Quantitative assessment of stakeholders' knowledge concerning aquatic invasive species

62 (AIS) is a critical first step in facilitating optimal human behaviors and developing stakeholders

63 support for effective management strategies. For example, an econometric investigation of AIS

64 awareness and knowledge determinants of near-lake property owners revealed that college- 
65 educated water recreationists and boat owners who visited lakes outside their area are more

66 likely to be aware of different aspects of AIS compared to non-recreationists (Eiswerth et al.

67 2011). In general, active members of formal associations (e.g., lake stewardships, fishing groups)

68 are more likely to be knowledgeable about AIS and less prone to engage in risky behaviors than

69 non-members, even when the latter exhibited some understanding of AIS issues (Gates et al.

70 2009; Eiswerth et al. 2011). However, those exhibiting passive membership in such

71 organizations may falsely report a degree of higher environmental awareness than is supported

72 by their factual knowledge (Heck et al. 2016). Low levels of awareness and concern can also

73 lead to risky behaviors associated with AIS spread, such as incomplete cleaning of personal

74 items and equipment (Gates et al. 2009). Overall, surveys suggest that fishers are more

75 knowledgeable about AIS and outreach campaigns than other recreationists (water skiers,

76 swimmers, etc.), but their participation in AIS prevention behaviors is inconsistent or low and

77 depends on fishing experience (Edwards et al. 2016; Eiswerth et al. 2011; Gates et al. 2009;

78 Lindgren 2006; Seekamp et al. 2016).

As with other environmental issues (Dean et al. 2016) preventative behaviors are usually

80 positively correlated with stakeholders' AIS knowledge (Gates et al. 2009), but confounding or

81 undesirable outcomes can arise despite high understanding of AIS. For example, transient

82 boaters are more likely to reuse the same bait in different water bodies compared to other

83 boaters, even though all boaters tend to have attitudes and beliefs that support AIS spread

84 prevention (Witzling et al. 2016). Some studies have found that even educated fishers are likely

85 (25-33\%) to release live bait into water bodies (Lindgren 2006; Drake et al. 2014). Similarly,

86 well-informed fishers and boaters often did not properly rinse used equipment (Connelly et al. 
2016; Seekamp et al. 2016). Disposition for risky behavior may be attributed to stakeholders tendency to underestimate the ecological costs of individual actions (Drake et al. 2014).

Additionally, trans-situational or situational predictors of AIS knowledge may also affect the success of AIS outreach and education campaigns (Eiswerth et al. 2011). Trans-situational

91 factors are variables that generally remain static regardless of the situation (e.g., age, sex and 92 education). These variables have been shown to influence levels of environmental knowledge in 93 many countries (Dean et al. 2016; Heck et al. 2016; Pierce et al. 2010; Steel et al. 2005a; Steel et 94 al. 2005b). Better educated, older, males tend to be more knowledgeable about public policy 95 issues, although the gender gap is closing in the younger population (Otto and Kaiser 2014; 96 Pierce et al. 2010; Steel et al. 2005a; Steel et al. 2005b), and may be becoming more dependent 97 on the specific environmental issue (Dean et al. 2016; Harvey et al. 2016; Otto and Kaiser 2014).

98 In contrast, context-dependent situational variables arise as a result of encounters between 99 individuals and their environments irrespective of individual characteristics like age, sex and 100 education (Belk 1975; Dean et al. 2016; Heck et al. 2016; Pierce et al. 2010; Steel et al. 2005a; 101 Steel et al. 2005b). Situational factors are impacted by the degree of exposure to the issue and in 102 turn, influence knowledge-seeking behavior of the stakeholders (Steel et al. 2005a; Steel et al. 103 2005b). Trans-situational and situational factors can interact to influence the ontogeny of 104 environmental awareness and knowledge, but situational factors can also help override the 105 influence of trans-situational factors. For example, coastal recreationists are more likely to be 106 knowledgeable about important ocean and coastal issues regardless of individual trans-situational 107 profiles (e.g., Steel et al. 2005a; Steel et al. 2005b). Given their static nature, trans-situational 108 predictors are inherently more difficult to address through outreach and education campaigns, 109 whereas pliable situational predictors are more receptive to communications strategies. By 
110 identifying AIS knowledge predictors and understanding their characteristics, managers have the 111 opportunity to influence AIS knowledge by engaging in more targeted outreach which can lead 112 to better AIS management successes.

113 This study aims to assess the knowledge base of diverse stakeholders associated with

114 freshwater and sub-saline lakes of the Northern Great Plains of the Canadian prairies. Lakes are 115 abundant in Saskatchewan (SK), Canada, and provide important ecosystem services and 116 economic opportunities (Koob and McGuire 2013; Leavitt et al. 2006; Wissel et al. 2011), and 117 AIS are a critical threat to water quality, native flora and fauna, recreation, and economic 118 investments (Dextrase and Mandrak 2006; Pimentel et al. 2005). Additional information about 119 the study region can be found in Nanayakkara and Wissel (2017). Several AIS are already 120 present in SK and, given its geographic position, the region is considered highly vulnerable to a 121 non-native mussel invasion (Provincial Auditor 2016). The most recent evaluation of the 122 effectiveness of AIS outreach and education efforts was conducted in 2010 as part of a joint 123 Federal-Provincial survey of sport-fishing in SK (Koob and McGuire 2013). Results indicated 124 low levels of awareness (23\%) among SK residents about AIS outreach efforts and similar to 125 studies discussed earlier, identified risky watercraft use patterns that may exacerbate 126 vulnerability to non-native mussels (Koob and McGuire 2013). Therefore, despite increased AIS 127 outreach and education efforts (including a formal mussel strategy initiated in 2014), we contend 128 that attempts to influence knowledge and foster preventative behaviors via communications 129 campaigns have been ineffective in SK. We posit instead that knowledge and attitudes of the 130 regional stakeholders towards AIS are mainly informed by trans-situational factors, particularly 131 education. Specifically, in the present study, we seek to: 1) examine AIS knowledge levels 132 among stakeholders to measure effectiveness of current outreach efforts; 2) evaluate the 
133 contribution of trans-situational, situational and knowledge-related variables to identify targeted

134 outreach to increase AIS knowledge, and; 3) offer management recommendations based on

135 findings to help ensure prevention and control of AIS.

\section{Methods}

137 Data for this study were obtained from the Prairie Lake Use and Management Survey

138 (PLUMS), a 4-page self-administered questionnaire instrument that contained fixed and open-

139 ended questions. Prior to the survey, the questionnaire was pretested in 2013 to enhance the

140 instrument's validity and reliability (Nanayakkara and Wissel 2017). On the basis of this pilot

141 study, we eliminated inconsistencies in the questionnaire and the survey was expanded to include

142 AIS questions. The current questionnaire included five sections: lake-use information such as

143 purpose of lake-use and fishing habits; knowledge of aquatic systems including awareness of

144 eutrophication and winterkill; knowledge of invasive species; lake management strategies,

145 including satisfaction with lake management and willingness to participate in a citizen science

146 initiative, and; demographic information. Given the relatively small sample size in the 2013

147 study (65 respondents), we presented the survey in two formats, a paper as well as a web-

148 version.

149 We utilized multiple methods for survey distribution and outreach to maximize

150 participation. The survey was distributed in August 2015 using an on-site, convenience intercept

151 survey methodology at entrance and exit points of nine study lakes in SK (Floyd et al. 1997; Luo

152 and Deng 2008; Pan and Ryan 2009; Uysal et al. 1994). Sites chosen represent popular visitor

153 destinations and a range of sizes and distances from population centers in the region (Figure 1).

154 We approached 250 people on-site at beaches, boat ramps and park entrances at study lakes.

155 Survey participants chose to complete the survey right away, mail it at a later time 
156 (stamped/addressed envelope was provided) or complete it online (link was provided) at a time

157 of their convenience. Complete questionnaires were collected by interviewers (the lead author

158 was the principal interviewer) on-site once they were filled out by participants. If a group of

159 visitors was encountered, one to three (depending on the group size and composition)

160 representatives from the group were asked to fill out questionnaires. On average, respondents

161 spent 15 minutes filling out the questionnaires. Recruitment fliers with the web-link to the survey

162 were placed on every other vehicle windshield in the parking lot as well. We conducted

163 additional outreach and participant recruitment through articles (with web-link to the survey) in

164 local newspapers and through community members. The web version was available from August

1652015 to November 2015. Incentive for survey participation was provided through a prize draw to

166 win one of three fishing rods (each valued at CAD \$89.99). Questionnaire format ensured

167 anonymity but contact information was needed for prize draw participation. Approval to

168 complete this study was obtained from the University of Regina research ethics board.

169 We utilized a subset of questions on AIS and potential knowledge predictors (trans-

170 situational, situational and lake-related knowledge) from the PLUMS survey for this study

171 (Appendix 1). In additional 'yes/no' questions participants indicated awareness of the term

172 'invasive species’ as well as zebra (Dreissena polymorpha) and quagga (Dreissena bugensis)

173 mussels. Zebra and quagga mussels are currently absent in SK, but have been detected in waters

174 to the south, east and west of the study location (Benson et al. 2017; personal communications

175 with SK Ministry of Environment 2016). Given the potential for an invasion by these non-native

176 mussels and the economic consequences of such an invasion (Robinson et al. 2013; Strayer

177 2009), the SK Ministry of Environment has included an information pamphlet in the Anglers'

178 Guide since 1993 and initiated a strategy in 2014 to curtail arrival of non-native mussels. 
179 Analyses of public knowledge about non-native mussels were expected to help assess the 180 successes and failures of these outreach efforts. The matrix formatted AIS question section included the two mussels and a list of six

182 invasive species found in the province. It consisted of a series of 16 'yes/no' questions about:

183 three fishes: common carp (Cyprinus carpio), goldfish (Carassius auratus), koi (domesticated

184 ornamental varieties of Cyprinus carpio) three plants: flowering rush (Butomus umbellatus), 185 purple loosestrife (Lythrum salicaria), salt cedar (Tamarix ramosissima, Tamarix chinensis, 186 Tamarix parviflora), and two mussels. Eight questions asked respondents about their knowledge 187 of presence or absence of a specific (fish, plant and mussel) organism and eight questions probed 188 respondents about their knowledge of the negative impacts of each organism. Six questions 189 asked about presence/absence and impact of fish organisms (common carp, goldfish and koi), six 190 questions asked about presence/absence and impact of plant organisms (flowering rush, salt 191 cedar, and purple loosestrife) and 4 asked about presence/absence and impact of mussel 192 organisms (zebra mussels and quagga mussels). For knowledge of presence or absence of 193 invasive species, we modelled each of the three outcome variables as the number of correct 194 answers given per species for each type of organism (fish, plant and mussel) separately. We did 195 the same for correct knowledge of negative impact of invasive species, separately for each type 196 of organism. This lead to the construction of six separate outcome variables that conveyed 197 information about the number of correct answers regarding knowledge of presence/absence and 198 impacts of AIS by type of organism. From this information, we assessed participants' knowledge 199 of invasive species and used information from other relevant sections of the survey to identify 200 trans-situational, situational and lake-related knowledge predictor variables associated with this 201 knowledge. 
We used univariate, bivariate and multivariate statistical techniques to define the

203 composition of respondents and quantify the relationship between the various trans-situational,

204 situational and lake-related knowledge variables, and the respondents' knowledge of AIS issues.

205 Data processing, management and statistical analyses were conducted using IBM's Statistical

206 Package for the Social Sciences (SPSS), Version 23. Univariate analyses provided descriptive

207 statistics for all variables, including frequency distributions for awareness of the term 'invasive

208 species', presence/absence, and impact of invasive species. Crosstab analyses with chi-square

209 tests conducted for all three groups of organisms examined the relationship between correctly

210 identifying presence/absence and the species' impacts. Regression analyses undertaken for each

211 group of organisms assessed the influence of predictors on the outcome variables, namely

212 presence/absence and impact of invasive species. Informed by the extant literature, our analyses

213 also controlled for socio-demographic characteristics previously shown to influence these

214 outcomes (e.g., Ansong and Pickering 2015; Bremner and Park 2007; Dean et al. 2016; Edwards

215 et al. 2016; Eiswerth et al. 2011; García-Llorente et al. 2008; Heck et al. 2016; Pierce et al. 2010;

216 Seekamp et al. 2016; Steel et al. 2005a), including respondent's sex, age, type of place of

217 residence, ethnicity, education, and self-identified socio-economic status. The reviewed literature

218 provided a reasonable basis for organizing these factors into a tentative conceptual model of

219 knowledge of presence/absence and impact of AIS (Figure 2). The operational definition of the

220 predictors considered in the analyses are presented in Appendix 2. Dummy coded variables were

221 created for all categorical variables.

222 A series of regression analyses were performed to model the effects of the selected

223 predictors on the six outcome variables. Stepwise variable selection procedure was applied to help

224 select the "best" (most parsimonious) subset of predictors by removing redundant predictors, as

225 unnecessary predictors add noise. The 95\% significance level was used as a cut-off for statistically 
226 significant results. At each step, all eligible variables are considered for removal and entry till no

227 more variables are eligible for inclusion or removal; thus, leading to more parsimonious models

228 (Tabachnick and Fidell 2006). Because of the concern that linear regression is not always well-

229 suited for analyzing these kinds of "limited dependent variables" (e.g., Cameron \& Trivedi 2005;

230 Long 1997, 2005; Wooldridge 2013), we also conducted count regression analyses (e.g., Poisson

231 Regression, Negative Binomial Regression) to ensure our results are robust (results not reported

232 here). Ultimately, we are presenting the results of the linear regression because there were no

233 major differences in terms of statistical significance, direction of association, and model fitness

234 in the findings by technique used, and multiple linear regression is a more intuitive model for an

235 interdisciplinary audience to interpret and understand. We also examined frequency distributions

236 of zebra and quagga mussel awareness (yes/no), and conducted forward conditional stepwise

237 logistic regression analyses to identify significant predictors of mussel awareness.

238 The AIS question section also included open-ended questions probing respondents to

239 explain the cleaning procedure for a boat with mussels on it and to identify who they would

240 contact if mussels were discovered on a boat. Content analysis was used to categorise the

241 respondents' answers to these questions (Neuman and Robson 2011). For this analysis, we

242 examined common themes about contaminated boat cleaning procedures ('clean, drain, dry') and

243 who to contact (SK Ministry of Environment TIP 'Turn In Poachers' line) in the event of

244 discovering mussels on a boat. Additionally, answers were scrutinized for a clear indication of

245 knowledge about the need to 1) clean a contaminated boat using high pressure, hot tap water

$246\left(50^{\circ} \mathrm{C}\right)$ thoroughly scrubbing and rinsing surfaces; 2$)$ drain all onboard water (including motor,

247 livewell, bilge and bait buckets); and 3) dry contaminated boat and all gear for five days in the 
248 hot sun (if unable to rinse). Answers to this question were categorized as correct, incorrect or

249 partially correct (if the answer contained some aspect of 'clean, drain and dry').

$250 \quad$ Results

A total of 476 participants filled out the survey questionnaire. Overall, the online option

252 was more widely used than the in-person paper survey. We received 427 survey submissions

253 online while only 49 opted to fill out the paper copy on-site. A comparison of the demographic

254 characteristics of survey respondents to the general Saskatchewan population revealed that in our

255 sample, only $4.6 \%$ of respondents identified as First Nations compared to $15.6 \%$ of the SK

256 population identified as First Nations in the National Household Survey (Statistics Canada

257 2011). Unfortunately, additional outreach efforts in January and February 2016 did not

258 significantly increase First Nations recruitment in the survey and these communities remain 259 underrepresented.

260 Many participants visited lakes in at least two geographic regions in the province (44.3\%,

$261 n=211$, and single-region visitors were most common on lakes along the west-to-east draining

262 Qu'Appelle River catchment (20.6\%,n=98) (Appendix 3). Overall, lakes were used mostly for

263 fishing, swimming, boating, and recreation (activities other than fishing and swimming)

264 purposes, with some differences between regions in terms of lake-use purpose (Appendix 4). A

265 total of 36 respondents (7.6\%) did not use lakes in Saskatchewan and were excluded from

266 subsequent analyses.

267 Most respondents were aware of the term 'invasive species’ (92.4\%). Many were also

268 aware of presence of carp in SK waters (79.5\%) and about half were aware of purple loosestrife

269 (51.1\%), but most respondents were unaware of the presence of goldfish (58.0\%), koi (58.5\%),

270 flowering rush (88.4\%) and salt cedar (93.7\%) (Table 1). Additionally, many participants were 
271 unaware that zebra (72.6\%) and quagga (76.0\%) mussels had not yet colonized waterways in the

272 province (Table 1). Only about $33 \%$ of respondents had heard about quagga mussels, but a

273 majority of respondents (86.7\%) had heard about zebra mussels (Appendix 5). Many (80.3\%

274 zebra mussels and 58.3\% quagga mussels) participants were, however, aware of the negative

275 impacts of exotic mussels (Table 1). In contrast, most respondents were unaware of the potential

276 negative impact of flowering rush and salt cedar on native ecosystems, and only half of them had

277 an understanding of the potential negative impacts of goldfish (Table 1). Crosstabulations with

278 chi-square tests yielded significant $(\mathrm{p}<0.001)$ positive relationships between correctly identifying

279 presence/absence of a given organism and correctly identifying negative impact of that organism

280 for all three groups (Table 2).

281 Regression analyses identified the importance of trans-situational, situational and lake-

282 related knowledge predictors associated with correctly identifying presence/absence (Table 3,

283 see also Figure 3) and impacts of AIS in southern Saskatchewan (Table 4, see also Figure 4).

284 Specifically, fishing and awareness of lake-related environmental issues (eutrophication,

285 winterkill, and industrial water extraction) were positively and significantly related to correctly

286 identifying the presence of fishes. Age, rural residence (compared to residence in medium or

287 large cities), swimming, and recreation were all negatively associated with correctly identifying

288 the presence of fishes. In contrast, older participants, and those who used all three lake regions,

289 or used lakes for work, and aware of eutrophication were more likely to be knowledgeable of

290 presence of listed plants. Similarly, using all three lake regions, using lakes for work and

291 awareness of eutrophication were positively and significantly related to correctly identifying

292 absence of invasive mussels in SK waters. Awareness of eutrophication was a significant

293 predictor of presence/absence knowledge for all three groups of organisms (Table 3, Figure 2). 
294 More educated respondents and fishers were more knowledgeable about the negative impacts of 295 all AIS (Table 4, Figure 3). Males and those aware of industrial water extractions were more 296 knowledgeable of the negative impact of invasive fishes, whereas age was inversely related to 297 awareness of negative impact of invasive fishes. In turn, those aware of both eutrophication and 298 water extraction were more likely to correctly identify negative impact of plants. Swimmers, on 299 the other hand, were significantly less likely to be familiar with negative impacts of both plants 300 and mussels. Male respondents using all three lake regions, and those aware of eutrophication 301 were more knowledgeable about impacts of mussels. Awareness of eutrophication increased the 302 likelihood of having heard about both zebra and quagga mussels (Table 5). Additionally, better 303 educated, older males were more likely to have heard about zebra mussels and those using lakes 304 for work were more likely to have heard about quagga mussels, while respondents using lakes 305 for seasonal cabins were less likely to have heard about quagga mussels. Only $5.7 \%$ of participants correctly answered 'clean, drain, dry' as the best method to 307 prevent a mussel invasion, whereas $61.1 \%$ were aware of at least one step, and one-third (33.2\%) 308 were completely unaware of recommended cleaning processes. Among those who correctly 309 identified the need to dry the infected boat, there was no consensus on length of drying time, 310 with responses ranging from 72 hours to 90 days to 'let it freeze over winter'. Similarly, 311 participants aware of the need to clean the boat did not identify a uniform protocol, with answers 312 including using household bleach, domestic cleaning substances, vinegar, muriatic acid, chlorine, 313 disinfectant, chemical treatments, poisons, acid-based cleaners, dish washing detergent, bug 314 killer and pesticides. Regarding who to contact in the event of mussel discovery, only $4.4 \%$ 315 correctly stated the SK government TIP telephone line, while $72.1 \%$ stated various levels of 316 government, ranging from the local municipality's office, to the local Conservation Officer, 
317 specific provincial ministries, federal agencies (e.g., Environment Canada, Fisheries and Oceans

318 Canada), or the Royal Canadian Mounted Police (RCMP), a federal law enforcement agency in

319 Canada. Almost a quarter (23.5\%) of participants did not know who to contact or simply would

320 not contact any authority if mussels were found.

321 Discussion

Our study highlights the dynamic nature of AIS knowledge among stakeholders. Findings

323 suggest that current outreach and communication methods are either ineffective at reaching

324 desired audiences or important information is not being retained, or a combination of the two. As

325 noted elsewhere (Dean et al. 2016; Eiswerth et al. 2011; Steel et al. 2005a; Steel et al. 2005b),

326 the regression analyses identified trans-situational (e.g., age, sex, education), situational (e.g.,

327 mode and location of recreation) and lake-related knowledge (e.g., eutrophication) predictors.

328 Consistent with prior analyses of AIS knowledge across organisms (Lindgren 2006; Strayer

329 2009), respondents were more aware of effects and presence of invasive fishes than plants.

330 Surprisingly, substantial knowledge gaps were identified concerning the presence and prevention

331 of non-native mussel transmission. In our study, awareness of eutrophication was found to be a

332 simple but near-universal predictor of respondent's knowledge concerning AIS, while previous

333 studies identified breadth and depth of recreational involvement as near-universal predictors

334 (Eiswerth et al. 2011; Seekamp et al. 2016). Therefore, our study provides further evidence for

335 the overall importance of lake-based activities and lake-related knowledge as determinants of

336 AIS knowledge. Based on our results, we propose that future management strategies focus on

337 improving communications by streamlining outreach messages, targeting low-knowledge groups

338 (e.g., swimmers, cabin owners), and expanding education campaigns. 
Although most respondents were aware of the term 'invasive species', knowledge about

341 presence/absence and impacts of AIS was organism-dependent. Overall knowledge of invasive

342 fishes was greater than that of invasive plants. This observation may be an extension of the

343 general bias towards an increased interest in animals over plants (Martín-López et al. 2007). It

344 may also be a reflection on the regulation of non-native animals (Ministry of Environment) and

345 plants (Ministry of Agriculture) by separate ministries with different communications strategies

346 (Provincial Auditor 2016). Relatively high knowledge about presence and impacts of carp may

347 be attributed to attention in the media, its inclusion in the annual Anglers' Guide, and the

348 presence of a commercial fishery that was operational until the 1980's. In contrast, goldfish are

349 often purchased as pets and koi are ornamental species, thus, familiarity with them in these

350 contexts may limit concern over their environmental impacts relative to carp (Lindemann-

351 Matthies 2016; Shackleton and Shackleton 2016; Touza et al. 2014). Comparable to findings in

352 neighboring Manitoba (Lindgren 2006), most respondents did not know about the presence or

353 negative impacts of invasive plants such as flowering rush and salt cedar. However, similar to

354 Lindgren (2006), many respondents correctly identified presence and negative impact of purple

355 loosestrife. In this instance increased familiarity may be attributed to its identification and

356 description as an aquatic invasive plant on the Government of SK (Ministry of Environment)

357 website.

358 Mussels

As shown in previous studies (Strayer 2009), respondents exhibited variable knowledge

360 about invasive mussels. Despite low awareness of mussel absence in SK, many respondents

361 correctly identified the negative impact of both invasive mussels, which may be attributed to the

362 high visibility of mussels through widespread media coverage in North America (Haag and 
363 Williams 2014; Strayer 2009). Results on mussel presence/absence should be of concern to

364 managers, government, stakeholders and scientists alike because if non-expert stakeholders

365 incorrectly assume SK waters have already been invaded by mussels or are unaware of their

366 status in the province, they may be less inclined to engage in preventative and/or control

367 behaviors, as seen elsewhere (Drake et al. 2015; Gates et al. 2009).

368 Inconsistent nature of the answers to the open-ended questions provides evidence that

369 current outreach efforts are either not delivering the message in a clear, understandable manner

370 or that it is not being retained. The message of 'clean, drain, dry' is a central tenant of invasive

371 mussel prevention and control campaigns around the world (Gates 2009; Seekamp et al. 2016;

372 Zook and Phillips 2012), and needs to be delivered successfully to recreationists utilizing water-

373 crafts to prevent mussel invasion. Even when water-craft users are willing to drain their boats,

374 they are unlikely to use a hot water rinse as recommended (Connelly et al. 2016; Seekamp et al.

375 2016). Therefore, such a program needs to include better transmission of information on precise

376 protocols, as most respondents did not know the length of time a watercraft should be dried, or

377 the cleaning procedures needed to ensure adult mussels and veligers are completely removed

378 from contaminated boats and equipment. Of added concern is the predisposition of some

379 respondents to clean watercrafts with chemicals (only hot water is recommended in the protocol)

380 that are not only harmful to waterways but also to individuals themselves. Additionally, outreach

381 material should prominently display relevant contact information and emphasize the need to

382 contact authorities via the TIP line if watercraft is contaminated with mussels.

383 Role of predictors 
As organized in Figure 1, this study explored the impact of a number of trans-situational,

385 situational, and lake-related knowledge factors related to AIS knowledge. Consistent with

386 previous studies, certain trans-situational variables were important predictors of invasive species

387 knowledge. While increased respondent age is generally associated with higher levels of

388 environmental awareness (Lindgren 2006; Steel et al. 2005a), the relationship between age and

389 knowledge in our study was less straightforward. We are unsure about the exact causes behind

390 the heterogeneity (negatively associated with fishes but positively associated with plants) of the

391 influence of age on AIS knowledge. The positive influence of age on environmental awareness is

392 partly attributed to the accumulated impact of exposure to environmental information since the

393 1960s environmental awareness movement (Otto and Kaiser 2014). Even though past empirical

394 research indicates that the relationship between sex and environmental awareness is complicated

395 (Harvey et al. 2016; Otto and Kaiser 2014), males in our study were generally more

396 knowledgeable about invasive fish impacts, more aware of zebra mussels' colonization patterns,

397 and more informed of mussel impacts on the environment. Consistent with the observation that

398 level of formal education is an important predictor of AIS awareness (Eiswerth et al. 2011), we

399 noted that education was associated positively with increased knowledge of negative impacts of

400 fishes, plants and mussels. Finally, residential location was an important predictor of AIS issues,

401 as rural residents were less likely to be knowledgeable about fish presence than urban

402 participants. These "non-modifiable" predictors are more static compared to contextually

403 impressionable situational and knowledge predictors (Steel et al. 2005a) and therefore,

404 management efforts should prioritize situational predictors and focus less on trans-situational

405 variables. 
In our study, we identified several key situational factors. Fishing was an important

407 predictor of AIS knowledge. This effect is generally attributed to fishers increased familiarity

408 with invasive outreach information and campaigns, better developed sense of personal

409 responsibility to control AIS, and engagement in preventive behaviors (Edwards et al. 2016;

410 Eiswerth et al. 2011; Seekamp et al. 2016). Higher knowledge of the presence of plants and

411 absence of mussels and their negative impacts among respondents who used all three lake

412 regions and used lakes for work may be due to repeated interactions with lake environments.

413 Such interactions often result in more positive experiences with that environment, increase

414 environmental concern and acts as a situational motivator to promote knowledge-seeking

415 behavior (Eiswerth et al. 2011; Steel et al. 2005a; Steel et al. 2005b).

Not all situational predictors were positively correlated with increased understanding of

417 AIS issues. For example, use of lakes for recreational swimming was associated negatively with

418 knowledge of fish presence, and impacts of both plants and mussels. Similar to Strayer's (2009)

419 findings, recreationists (non-fishing/non-swimming) were also generally less knowledgeable

420 about the presence of invasive fish organisms. Additionally, cabin-use was related negatively to

421 awareness of quagga mussels. Possibly, recreationists and cabin owners are more concerned

422 about other well-publicized threats to their lakes (e.g., eutrophication, industrial water extraction,

423 pesticide exposure, etc.) (Eiswerth et al. 2011). Low knowledge among cabin-users may also be

424 attributed to the highly seasonal nature of cabin use in SK, which may limit cabin owners'

425 contact with lake-relevant information, including AIS.

In addition to trans-situational and situational predictors of AIS knowledge, knowledge of

427 lake-related environmental issues increased understanding of AIS-related issues. In particular,

428 awareness of eutrophication was a near-universal predictor of AIS for both presence/absence and 
429 impact. Noxious summer algal blooms have been reported in southern Saskatchewan since the

430 early $20^{\text {th }}$ century (Rawson and Moore 1944), and have become a well-publicized water quality

431 issue that has resulted in upgrades (> CAD \$200 million) to the City of Regina wastewater

432 treatment plant (CCPPP 2014). Similarly, industrial water extractions from Qu'Appelle Valley

433 lakes have been prominent in the media for over five years (WSA 2012), possibly explaining its

434 linkage to knowledge of AIS-related topics (fish presence, fish impacts and plant impacts).

435 Likely, exposure to lake-related environmental issues such as eutrophication or industrial water

436 extraction has engendered greater overall knowledge about lakes through stimulation of

437 knowledge-seeking behavior, as seen elsewhere (Dean et al. 2016; Steel et al. 2005a; Steel et al. 438 2005b).

Management implications

Low levels of AIS knowledge recorded across all organisms indicate a need to critically

441 evaluate current outreach and communication efforts. Our findings echo results from an earlier

442 survey (Koob and McGuire 2013) that outreach campaigns are not effectively reaching the

443 desired audience. Many factors may contribute to reduced effectiveness, including: stakeholders

444 inability to recall campaign messages (Seekamp et al. 2016); public preference for new or non-

445 traditional media (e.g., Twitter, Facebook) not employed by managers (Koob and McGuire

446 2013); messages are convoluted or overly-complex (technical) (Seekamp et al. 2016); strategies

447 place insufficient emphasis on personal responsibility and potential damages (Drake et al. 2015;

448 Seekamp et al. 2016; Strayer 2009) and; unreceptive or inattentive stakeholders (Drake et al.

449 2015). We recommend a focus group methodology that includes a variety of stakeholders to help

450 identify mechanisms responsible for campaign ineffectiveness and how strategies should be

451 modified to enhance message retention and recall. A dual outreach portfolio may be particularly 
452 effective, with education and outreach campaigns expanded province-wide, utilizing multiple 453 social media formats (blogs, Twitter, Facebook) in addition to more traditional media avenues

454 (television, radio, print), while also directly providing critical information at each lake to

455 increase awareness of AIS. In particular, we suggest that campaign developers and implementers

456 be cognizant of the need to keep the AIS information direct, concise, and jargon-free (Shu and

457 Carlson 2014). We also recommend careful study of similar campaigns underway in comparable 458 regions to determine their effectiveness before implementation.

459 Along with expansion of education and communication strategies, managers should 460 target the use of situational information identified from the findings of the present study to 461 increase knowledge levels in individual groups. For example, to capitalize on the positive 462 relationship between multiple-lake use and AIS knowledge, the province could use tourist 463 advertising or competitions to encourage stakeholders to visit many lakes. Targeting information 464 at non-fishing/boating recreationists may be more effective in improving general understanding 465 than primarily posting information boards at fishing sites. It is important to draw connections 466 between recreationists desired lake-related activity and the impact of AIS. For example, bird467 watchers should be informed about potential decreases in food, shelter and nesting areas due to 468 purple loosestrife encroachment. Similarly, cabin-owners could be educated about detrimental 469 impacts of mussels on their personal infrastructure (water intake pipes, swimming) and property 470 values to address the inverse relationship between cabining and quagga mussel awareness. While 471 recreationists and cabin-users may not be direct vectors of AIS dispersal, increased engagement 472 by this group may help apply pressure to boat-owning or fishing neighbors to be more attentive 473 to AIS transmission. In particular, the strong positive association between lake-relevant 474 knowledge and AIS knowledge illustrates benefits of increasing 'lake-literacy' among general 
475 stakeholders. More knowledgeable citizens are also more likely to support AIS management

476 efforts and engage in more responsible behaviors (Reed 2008; White and Ward 2010).

477 Based on our findings that stakeholders are poorly informed about the status of exotic

478 mussels in SK and the province's vulnerability to a mussel invasion, managers should develop a

479 long-term, multi-party AIS strategy focused on prevention (Leung et al. 2002; Lovell et al. 2006;

480 Sharp et al. 2016), early detection, and eradication (Vander Zanden et al. 2010). Invasive

481 mussels are now established in most regions surrounding SK, particularly at sites such as Lake

482 Winnipeg, which are directly linked to the Qu'Appelle drainage by river flow. Poor knowledge

483 about mussel presence, combined with uneven understanding of effective preventive behaviors,

484 makes the province especially vulnerable to invasive mussels along east-west corridors.

485 Therefore, we propose the development of a multi-stakeholder coalition between universities,

486 lake associations, fishing tournaments, recreation organizations and citizen science groups to

487 help prevent mussel contaminated watercrafts entering the province. Such a coalition may also

488 alleviate resource burdens and provide more buy-in for stakeholders. For example, once potential

489 invasion corridors are identified, industrial partners may be willing to provide necessary funding

490 to construct watercraft wash-stations, and well-trained community volunteers may be willing to

491 operate such stations.

492 Conclusions

493 Studies such as ours help understand important knowledge gaps about effectiveness of 494 invasive species outreach campaigns (Strayer 2009). Given the global significance of invasive 495 species in both aquatic and terrestrial environments, application of methods used and insights 496 gained from our study are not limited to prairie lakes. We found that public perceptions of AIS 
497 were organism-dependent, emphasizing the importance of addressing invasive species issues on 498 a context-specific basis. Results also highlight the need for a multi-stakeholder approach to 499 rectify low AIS knowledge. In particular, we feel it may be important to quantify knowledge 500 levels at the onset of the decision-making process, involve diverse stakeholders, and continue 501 knowledge assessments at regular intervals. A survey instrument similar to ours will help assess 502 baseline invasive species knowledge and evaluate effectiveness of outreach efforts. Results from 503 such a survey will be particularly applicable if questions are sourced (in part) from managers and 504 practitioners (Matzek et al. 2014). Assessing and understanding public knowledge about 505 environmental issues can be an invaluable tool that helps prioritize education, outreach and 506 management goals which may ultimately facilitate adoption of desired environmental behaviors.

507 Additionally, increased AIS knowledge may have a 'spill-over' effect and positively impact 508 knowledge seeking behavior about other issues (e.g., overfishing, industrial pollution) that affect 509 lakes, increasing overall 'lake literacy' levels. More knowledgeable citizens will, in turn, be able 510 to better engage in management decisions that impact the health of lakes. 
513 Ansong M, Pickering C (2015) What's a weed? Knowledge, attitude and behaviour of park $514 \quad$ visitors about weeds. PLoS One 10(8): $1-14$

515 Belk RW (1975) Situational variables and consumer behavior. J Cons Res 2(3): 157-64

516 Benson AJ, Richerson MM, Maynard E, Larson J, Fusaro A, Bogdanoff AK, Neilson M

517 (2017) Dreissena rostriformis bugensis. USGS Nonindigenous Aquatic Species Database, $518 \quad$ Gainesville (FL)

519 Bremner A, Park K (2007) Public attitudes to the management of invasive non-native species in $520 \quad$ Scotland. Biol Conserv 139(3-4): 306-314

521 Cameron AC, Trivedi PK (2005) Microeconometrics: Methods and applications. Cambridge $522 \quad$ University Press

523 Canadian Council for Public Private Partnerships [CCPPP] (2014) Regina wastewater treatment 524 plant upgrade project, Saskatchewan: Delivering clean and safe wastewater for a growing $525 \quad$ city.

526 Carlson AK, Vondracek B (2014) Synthesis of ecology and human dimensions for predictive management of Bighead and Silver carp in the United States. Rev Fish Sci Aquac 22(4): 284-300

532 Dean AJ, Fielding KS, Newton FJ (2016) Community knowledge about water: Who has better knowledge and is this associated with water-related behaviors and support for waterrelated policies? PLoS One 11(7): 1- 18 
Dextrase AJ, Mandrake NE, (2006) Impacts of alien invasive species on freshwater fauna at risk in Canada. Biol Invasions 8(1): 13 -24

Drake DAR, Mercader R, Dobson T, Mandrak NE (2014) Can we predict risky human behaviour involving invasive species? A case study of the release of fishes to the wild. Biol Invasions 17(1): 309-326

Edwards CJ, Heinen JT, Rehage JS (2016) Recreational angler perspectives of nonnative fishes. Hum Dimens Wildl 21(2): 144-157

Eiswerth ME, Yen ST, van Kooten GC (2011) Factors determining awareness and knowledge of aquatic invasive species. Ecol Econ 70(9): 1672-1679

Floyd MF, Jang H, Noe FP (1997) The relationship between environmental concern and acceptability of environmental impacts among visitors to two U.S. national park settings. J Environ Manage 51: 391 - 412

Ford-Thompson AES, Snell C, Saunders G, White PCL (2015) Dimensions of local public attitudes towards invasive species management in protected areas. Wildlife Res 42: 6074

García-Llorente M, Martín-López B, González JA, Alcorlo P, Montes C (2008) Social perceptions of the impacts and benefits of invasive alien species: Implications for management. Biol Conserv 141(12): 2969-2983

Gates KK, Guy CS, Zale AV, Horton TB (2009) Angler awareness of aquatic nuisance species and potential transport mechanisms. Fisheries Manag Ecol 16(6): 448-456

Haag WR, Williams JD (2014) Biodiversity on the brink: an assessment of conservation strategies for North American freshwater mussels. Hydrobiologia 735: 45 - 60 
557 Harvey RG, Perez L, Mazzotti FJ (2016) Not seeing is not believing: volunteer beliefs about

$558 \quad$ Burmese pythons in Florida and implications for public participation in invasive species

559 removal. J Environ Plan Manage 59(5): 789-807

560 Heck N, Paytan A, Potts DC, Haddad B (2016) Coastal residents' literacy about seawater

561 desalination and its impacts on marine ecosystems in California. Mar Policy 68: 178-186

562 Jetter K, Paine TD (2004) Consumer preferences and willingness to pay for biological control in

563 the urban landscape. Biol Control 30(2): 312-322

564 Koob M, McGuire C (2013) 2010 Survey of Sport Fishing in Saskatchewan. Prince Albert (SK):

$565 \quad$ SK Ministry of Environment.

566 Leavitt PR, Brock CS, Ebel C, Patoine A (2006) Landscape-scale effects of urban nitrogen on a

567 chain of freshwater lakes in central North America. Limnol Oceanogr. 51: 2262- 2277

568 Leung B, Lodge DM, Finnoff D, Shogren JF, Lewis MA, Lamberti G (2002) An ounce of

569 prevention or a pound of cure: bioeconomic risk analysis of invasive species. Proc R Soc

$570 \quad$ Lond [Biol] 269(1508): 2407-2413

571 Lindemann-Matthies P (2016) Beasts or beauties? Laypersons’ perception of invasive alien plant $572 \quad$ species in Switzerland and attitudes towards their management. NeoBiota 29: 15-33

573 Lindgren C (2006) Angler awareness of aquatic invasive species in Manitoba. J Aquat Plant

$574 \quad$ Manage 44: 103-108.

575 Long JS (1997) Regression Models for Categorical and Limited Dependent Variables. Sage.

576 Long JS (2005) Regression Models for Categorical Dependent Variables Using Stata. $2^{\text {nd }}$ edition.

$577 \quad$ Stata Press

578 Lovell SJ, Stone SF, Fernandez L (2006) The economic impacts of aquatic invasive species: A 579 review of the literature. Agr Resource Econ Rev 35(1): 195-208 
Luo Y, Deng J (2008) The new environmental paradigm and nature-based tourism motivation. J Travel Res 46: 392 - 402

Martín-López B, Montes C, Benayas J (2007) The non-economic motives behind the willingness to pay for biodiversity conservation. Biol Cons 139: 67 - 82

584 Matzek V, Covino J, Funk JL, Saunders M (2014) Closing the knowing-doing gap in invasive plant management: Accessibility and interdisciplinarity of scientific research. Conserv

Moon K, Blackman DA, Brewer TD (2015) Understanding and integrating knowledge to Lett 7(3): $208-215$ improve invasive species management. Biol Invasions 17(9): 2675-2689

Nanayakkara L, Wissel B (2017) Preliminary investigation of lake-use patterns in prairie lakes, stakeholder perceptions and resulting management implications. Lake Reserv Manage 33 (1): $1-14$

Neuman, WL, Robson K (2011) Basics of social research: Qualitative and quantitative approaches. $2^{\text {nd }}$ edition. Boston (MA): Pearson

594 Otto S, Kaiser FG (2014) Ecological behavior across the lifespan: Why environmentalism increases as people grow older. J Environ Psychol 40: 331-338

Pan S, Ryan C (2007) Mountain areas and visitor usage-motivations and determinants of satisfaction: The case of Pirongia forest park, New Zealand. J Sustainable Tour 15(3): $288-308$ energy policy. Comparative Technology Transfer and Society 7(3): 270-286 
603 Pimentel D, Zuniga R, Morrison D (2005) Update on the environmental and economic costs

604 associated with alien-invasive species in the United States. Ecol Econ 52: 273-288

605 Rawson DS, Moore JE (1944) The saline lakes of Saskatchewan. Can J Res 22: 141 - 201

606 Reed MS (2008) Stakeholder participation for environmental management: A literature review.

607 Biol Conserv 141(10): 2417-2431

608 Robinson DCE, Knowler D, Kyobe D, de la Cueva Bueno P (2013) Preliminary damage

609 estimates for selected invasive fauna in B.C. Report prepared for Ecosystems Branch,

610 B.C. Ministry of Environment, Victoria, B.C. by ESSA Technologies Ltd., Vancouver

$611 \quad$ (B.C.) $62 \mathrm{p}$.

612 Seekamp E, McCreary A, Mayer J, Zack S, Charlebois P, Pasternak L (2016) Exploring the

613 efficacy of an aquatic invasive species prevention campaign among water recreationists.

614 Biol Invasions 18(6): 1745-1758

615 Shackleton CM, Shackleton RT (2016) Knowledge, perceptions and willingness to control

616 designated invasive tree species in urban household gardens in South Africa. Biol

617 Invasions 18(6): 1599-1609

618 Sharp RL, Cleckner LB, DePillo S (2016) The impact of on-site educational outreach on

619 recreational users' perceptions of aquatic invasive species and their management.

$620 \quad$ Environ Educ Res 1-11

621 Sharp RL, Larson LR, Green GT (2011) Factors influencing public preferences for invasive alien

623 Shu SB, Carlson KA (2014) When three charms but four alarms: Identifying the optimal number 624 of claims in persuasion settings. J Marketing 78(1): 127-139 
625 Statistics Canada (2011) 2011 Census: population, urban and rural, by province (Saskatchewan). 626 Canada.

627 Steel B, Lovrich N, Lach D, Fomenko V (2005a) Correlates and consequences of public

628 knowledge concerning ocean fisheries management. Coast Manage 33(1): 37-51

629 Steel B, Smith C, Opsommer L, Curiel S, Warner-Steel R (2005b) Public ocean literacy in the $630 \quad$ United States. Ocean Coast Manage 48: 97-114

631 Strayer DL (2009) Twenty years of zebra mussels: Lessons from the mussel that made headlines. $632 \quad$ Front Ecol Environ 7(3): 135 - 141

633 Tabachnick BG, Fidell LS (2006) Using Multivariate Statistics. $5^{\text {th }}$ edition. Boston (MA):

$634 \quad$ Pearson and $\mathrm{AB}$

635 Touza J, Pérez-Alonso A, Chas-Amil ML, Dehnen-Schmutz K (2014) Explaining the rank order 636 of invasive plants by stakeholder groups. Ecol Econ 105: 330-341

637 Uysal M, Jurowski C, Noe FP, McDonald CD (1994) Environmental attitude by trip and visitor $638 \quad$ characteristics. Tourism Manage 15(4): 284 - 294

639 Vander Zanden MJ, Hansen GJA, Higgins SN, Kornis MS (2010) A pound of prevention, plus a 640 pound of cure: Early detection and eradication of invasive species in the Laurentian Great $641 \quad$ Lakes. J Great Lakes Res 36(1): 199-205

642 Water Security Agency [WSA] (2012) 25 year Saskatchewan water security plan. Moose Jaw 643 (SK)

644 White PCL, Ward AI (2010) Interdisciplinary approaches for the management of existing and 645 emerging human-wildlife conflicts. Wildlife Res 37: 623-629 
646 Wissel B, Cooper RN, Leavitt PR, Pham SV (2011) Hierarchical regulation of pelagic

647 invertebrates in lakes of the northern Great Plains: a novel model for interdecadal effects

648 of future climate change on lakes. Glob Change Biol 17(1): 172-185

649 Witzling L, Shaw B, Seiler D (2016) Segmenting boaters based on level of transience: outreach

650 and policy implications for the prevention of aquatic invasive species. Biol Invasions 18:

$651-12$

652 Wooldridge JM (2013) Introductory econometrics: A modern approach. $4^{\text {th }}$ edition. Nelson

$653 \quad$ Education

654 Zook B, Phillips S (2012) Uniform minimum protocols and standards for watercraft interceptions

655 programs for Dreissenid mussels in the western United States. Portland (OR): Pacific

656 States Marine Fisheries Commission.

657 
Figure 1. Map of study lakes in Saskatchewan, Canada. Inset identifies the location of the study area within the province. The Qu'Appelle River catchment consists of the following lakes: Pasqua, Echo, Katepwa, Crooked and Round. Surveys were distributed at Redberry, Wakaw, Lenore, Kipabiskau, Little Manitou, Fishing, Buffalo Pound, Last Mountain, and Echo lakes. Regina and Saskatoon are the major urban centers in Saskatchewan. 


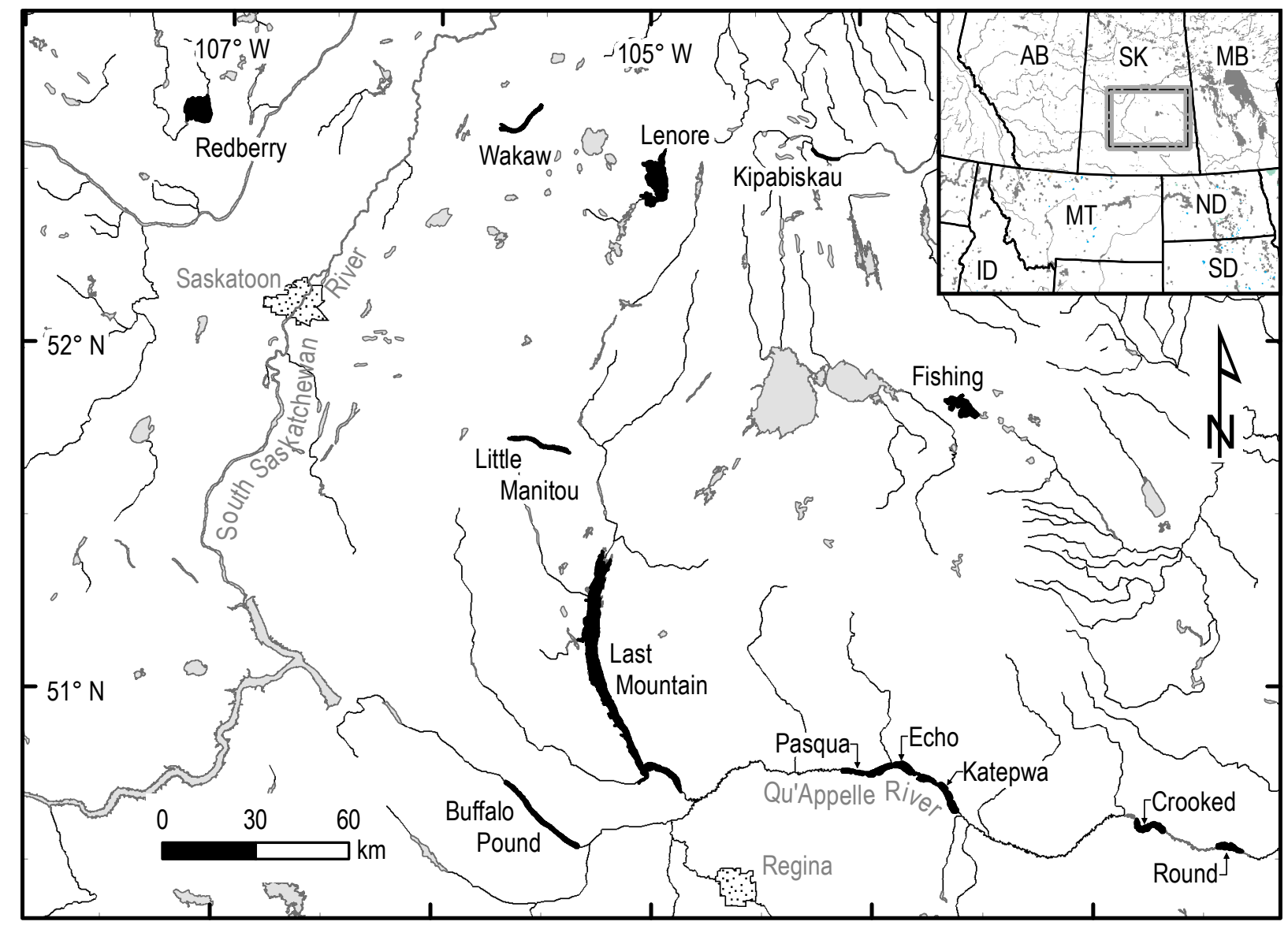


Figure 2. Conceptual framework of influence of trans-situational, situational, and lakerelated knowledge predictors on presence/absence and impact of AIS

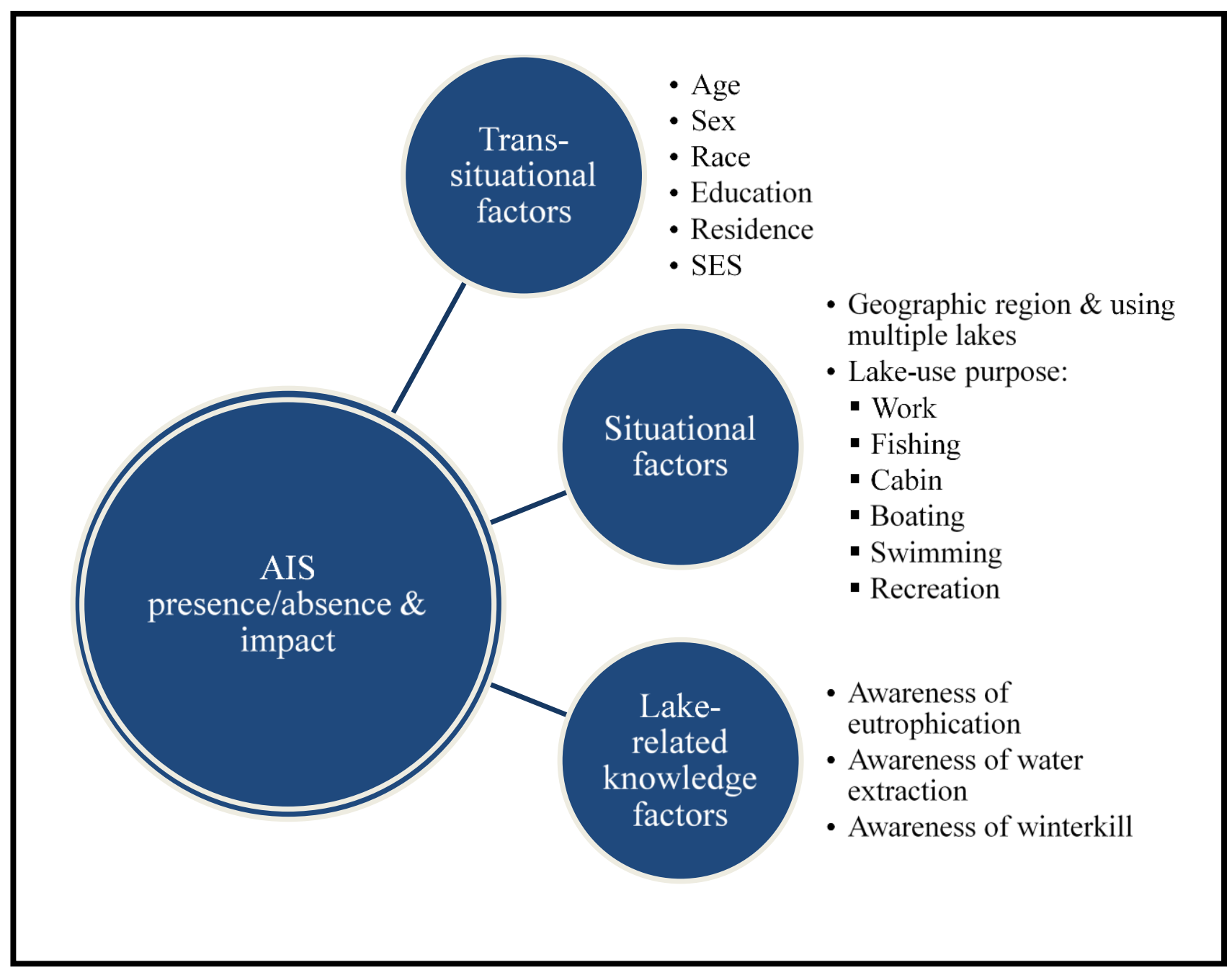


Table 1. Presence/absence and impact knowledge for each species, PLUMS 2015-2016

Presence/absence

Impact

\begin{tabular}{|c|c|c|c|c|c|c|}
\hline \multirow{2}{*}{ Species } & \\
\hline & Present & Absent & $\begin{array}{l}\text { Don't } \\
\text { know }\end{array}$ & Positive & Negative & $\begin{array}{l}\text { Don't } \\
\text { know }\end{array}$ \\
\hline Carp & $\begin{array}{c}79.5 \% \\
(n=333)\end{array}$ & $\begin{array}{c}3.3 \% \\
(n=14)\end{array}$ & $\begin{array}{c}17.2 \% \\
(n=72)\end{array}$ & $\begin{array}{c}12.8 \% \\
(n=52)\end{array}$ & $\begin{array}{c}61.5 \% \\
(n=249)\end{array}$ & $\begin{array}{c}25.7 \% \\
(n=104)\end{array}$ \\
\hline Goldfish & $\begin{array}{c}42.0 \% \\
(n=170)\end{array}$ & $\begin{array}{c}18.7 \% \\
(n=76)\end{array}$ & $\begin{array}{c}39.3 \% \\
(n=159)\end{array}$ & $\begin{array}{c}4 \% \\
(n=15)\end{array}$ & $\begin{array}{c}50.5 \% \\
(n=192)\end{array}$ & $\begin{array}{c}45.5 \% \\
(n=173)\end{array}$ \\
\hline Koi & $\begin{array}{c}41.5 \% \\
(n=169)\end{array}$ & $\begin{array}{c}13.5 \% \\
(n=55)\end{array}$ & $\begin{array}{c}45.0 \% \\
(n=183)\end{array}$ & $\begin{array}{c}2.9 \% \\
(n=11)\end{array}$ & $\begin{array}{c}53.1 \% \\
(n=199)\end{array}$ & $\begin{array}{c}44.0 \% \\
(n=165)\end{array}$ \\
\hline $\begin{array}{l}\text { Flowering } \\
\text { Rush }\end{array}$ & $\begin{array}{c}11.6 \% \\
(n=46)\end{array}$ & $\begin{array}{c}12.2 \% \\
(n=48)\end{array}$ & $\begin{array}{c}76.2 \% \\
(n=301)\end{array}$ & $\begin{array}{l}1.1 \% \\
(n=4)\end{array}$ & $\begin{array}{c}34.8 \% \\
(n=126)\end{array}$ & $\begin{array}{c}64.1 \% \\
(n=232)\end{array}$ \\
\hline Salt Cedar & $\begin{array}{c}6.3 \% \\
(n=25)\end{array}$ & $\begin{array}{c}14 \% \\
(n=55)\end{array}$ & $\begin{array}{c}79.7 \% \\
(n=315)\end{array}$ & $\begin{array}{c}0.8 \% \\
(n=3)\end{array}$ & $\begin{array}{c}31.1 \% \\
(n=110)\end{array}$ & $\begin{array}{c}68.1 \% \\
(n=241)\end{array}$ \\
\hline $\begin{array}{l}\text { Purple } \\
\text { Loosestrife }\end{array}$ & $\begin{array}{c}51.1 \% \\
(n=206)\end{array}$ & $\begin{array}{c}7.5 \% \\
(n=30)\end{array}$ & $\begin{array}{c}41.4 \% \\
(n=167)\end{array}$ & $\begin{array}{c}3.7 \% \\
(n=14)\end{array}$ & $\begin{array}{c}62.3 \% \\
(n=236)\end{array}$ & $\begin{array}{c}34.0 \% \\
(n=129)\end{array}$ \\
\hline $\begin{array}{l}\text { Zebra } \\
\text { mussels }\end{array}$ & $\begin{array}{c}36.3 \% \\
(n=151)\end{array}$ & $\begin{array}{c}27.4 \% \\
(n=114)\end{array}$ & $\begin{array}{c}36.3 \% \\
(n=151)\end{array}$ & $\begin{array}{c}3.3 \% \\
(n=13)\end{array}$ & $\begin{array}{c}80.3 \% \\
(n=314)\end{array}$ & $\begin{array}{c}16.4 \% \\
(n=64)\end{array}$ \\
\hline $\begin{array}{l}\text { Quagga } \\
\text { mussels }\end{array}$ & $\begin{array}{c}14.7 \% \\
(n=60)\end{array}$ & $\begin{array}{c}24.0 \% \\
(n=98)\end{array}$ & $\begin{array}{c}61.3 \% \\
(n=250)\end{array}$ & $\begin{array}{c}1.9 \% \\
(n=7)\end{array}$ & $\begin{array}{c}58.3 \% \\
(n=218)\end{array}$ & $\begin{array}{c}39.8 \% \\
(n=149)\end{array}$ \\
\hline
\end{tabular}

Note. Valid percent (\%, first row) and frequency ( $n$, second row). All fishes and plants are present in SK, mussels are absent. All AIS listed are associated with negative impacts. 
Table 2. Crosstabulations with chi-square tests for associations between correctly identifying presence/absence of a group of AIS and correctly identifying their negative impacts, PLUMS 2015-2016

\begin{tabular}{|c|c|c|c|c|c|}
\hline \multicolumn{6}{|c|}{ Correctly identified presence/absence (\%) } \\
\hline Impact & None & $\begin{array}{c}\text { One } \\
\text { organism }\end{array}$ & $\begin{array}{c}\text { Two } \\
\text { organisms }\end{array}$ & $\begin{array}{c}\text { Three } \\
\text { organisms }\end{array}$ & Chi-square \\
\hline Fishes & & & & & $170.684 *$ \\
\hline None correct & 70.0 & 31.4 & 24.4 & 10.8 & \\
\hline One correct & 10.0 & 41.5 & 16.7 & 8.1 & \\
\hline Two correct & - & 8.2 & 30.0 & 21.6 & \\
\hline Three correct & 20.0 & 18.9 & 28.9 & 59.5 & \\
\hline Plants & & & & & $295.439 *$ \\
\hline None correct & 76.3 & 13.6 & 8.8 & & \\
\hline One correct & 4.6 & 57.4 & 14.7 & 9.1 & \\
\hline Two correct & 1.4 & 8.0 & 41.2 & 9.1 & \\
\hline Three correct & 17.8 & 21.0 & 35.3 & 81.8 & \\
\hline Mussels & & & & & $52.816^{*}$ \\
\hline None correct & 34.4 & 8.7 & 16.9 & N/A & \\
\hline One correct & 23.8 & 43.5 & 4.8 & N/A & \\
\hline Two correct & 41.8 & 47.8 & 78.3 & N/A & \\
\hline
\end{tabular}


Table 3. Stepwise multiple linear regression for predictor variables associated with correctly identifying presence/absence of

fish, plant and mussel organisms, PLUMS 2015-2016

\begin{tabular}{|c|c|c|c|c|c|c|c|c|c|c|c|c|}
\hline \multirow[b]{3}{*}{ Predictor Variables } & \multicolumn{11}{|c|}{ Correctly identifying presence/absence of: } & \\
\hline & \multicolumn{4}{|c|}{ Fish Organisms } & \multicolumn{4}{|c|}{ Plant Organisms } & \multicolumn{4}{|c|}{ Mussel Organisms } \\
\hline & B & Beta & Sig. & $\begin{array}{c}\text { Model } \\
\text { Entry } \\
\end{array}$ & $\mathbf{B}$ & Beta & Sig. & $\begin{array}{c}\text { Model } \\
\text { Entry } \\
\end{array}$ & $\mathbf{B}$ & Beta & Sig. & $\begin{array}{c}\text { Model } \\
\text { Entry }\end{array}$ \\
\hline (Constant) & 1.775 & & 0.000 & & 0.044 & & 0.757 & & 0.320 & & 0.000 & \\
\hline Age & -0.011 & -0.152 & 0.003 & 5 & 0.008 & 0.159 & 0.003 & 3 & - & - & - & - \\
\hline \multicolumn{13}{|l|}{ City/Town/RM of Residence ${ }^{1}$} \\
\hline Rural area & -0.343 & -0.152 & 0.002 & 4 & - & - & - & - & - & - & - & - \\
\hline Small population center & - & - & - & - & - & - & - & - & - & - & - & - \\
\hline \multicolumn{13}{|l|}{ Lakes' Region $^{2}$} \\
\hline South of Diefenbaker Qu'Appelle & - & - & - & - & - & - & - & - & - & - & - & - \\
\hline North of Diefenbaker Qu'Appelle & - & - & - & - & - & - & - & - & - & - & - & - \\
\hline Two different lake regions were used & - & - & - & - & - & - & - & - & - & - & - & - \\
\hline All three lake regions were used & - & - & - & - & 0.228 & 0.122 & 0.020 & 4 & 0.213 & 0.108 & 0.038 & 3 \\
\hline Purpose: Fishing & 0.344 & 0.141 & 0.005 & 2 & - & - & - & - & - & - & - & - \\
\hline Purpose: Swimming & -0.332 & -0.145 & 0.006 & 3 & - & - & - & - & - & - & - & - \\
\hline Purpose: Work & - & - & - & - & 0.468 & 0.183 & 0.000 & 2 & 0.372 & 0.138 & 0.011 & 2 \\
\hline Purpose: Recreation & -0.250 & -0.113 & 0.031 & 8 & - & - & - & - & - & - & - & - \\
\hline Awareness of Eutrophication & 0.276 & 0.126 & 0.013 & 1 & 0.407 & 0.259 & 0.000 & 1 & 0.252 & 0.152 & 0.004 & 1 \\
\hline Awareness of Winterkill & 0.310 & 0.111 & 0.028 & 6 & - & - & - & - & - & - & - & - \\
\hline Awareness of Water Extraction & 0.266 & 0.112 & 0.026 & 7 & - & - & - & - & - & - & - & - \\
\hline$\overline{\mathbf{R}}$ & \multicolumn{4}{|c|}{0.453} & \multicolumn{4}{|c|}{0.379} & \multicolumn{4}{|c|}{0.272} \\
\hline R square & \multicolumn{4}{|c|}{0.206} & \multicolumn{4}{|c|}{0.144} & \multicolumn{4}{|c|}{0.074} \\
\hline
\end{tabular}

Note. ${ }^{1}$ Reference category = Medium-to-large population center: population of 30,000 or more; ${ }^{2}$ Reference category = Diefenbaker Qu'Appelle system; $(-)=$ Predictor variable did not enter the model. In each model, we entered the following predictors: respondent's sex, age, race, highest educational level, self-perceived SES, city/town/RM of residence, lake's region, purpose: fishing, purpose: swimming, purpose: boating, purpose: recreation, purpose: work, purpose: cabining, awareness of eutrophication, awareness of winterkill and awareness of water extraction. Dummy coded variables (no. of categories -1) were created for categorical predictors. 
Figure 3. Findings-based layout of the impact of trans-situational, situational, and lakerelated knowledge predictors on presence/absence of AIS

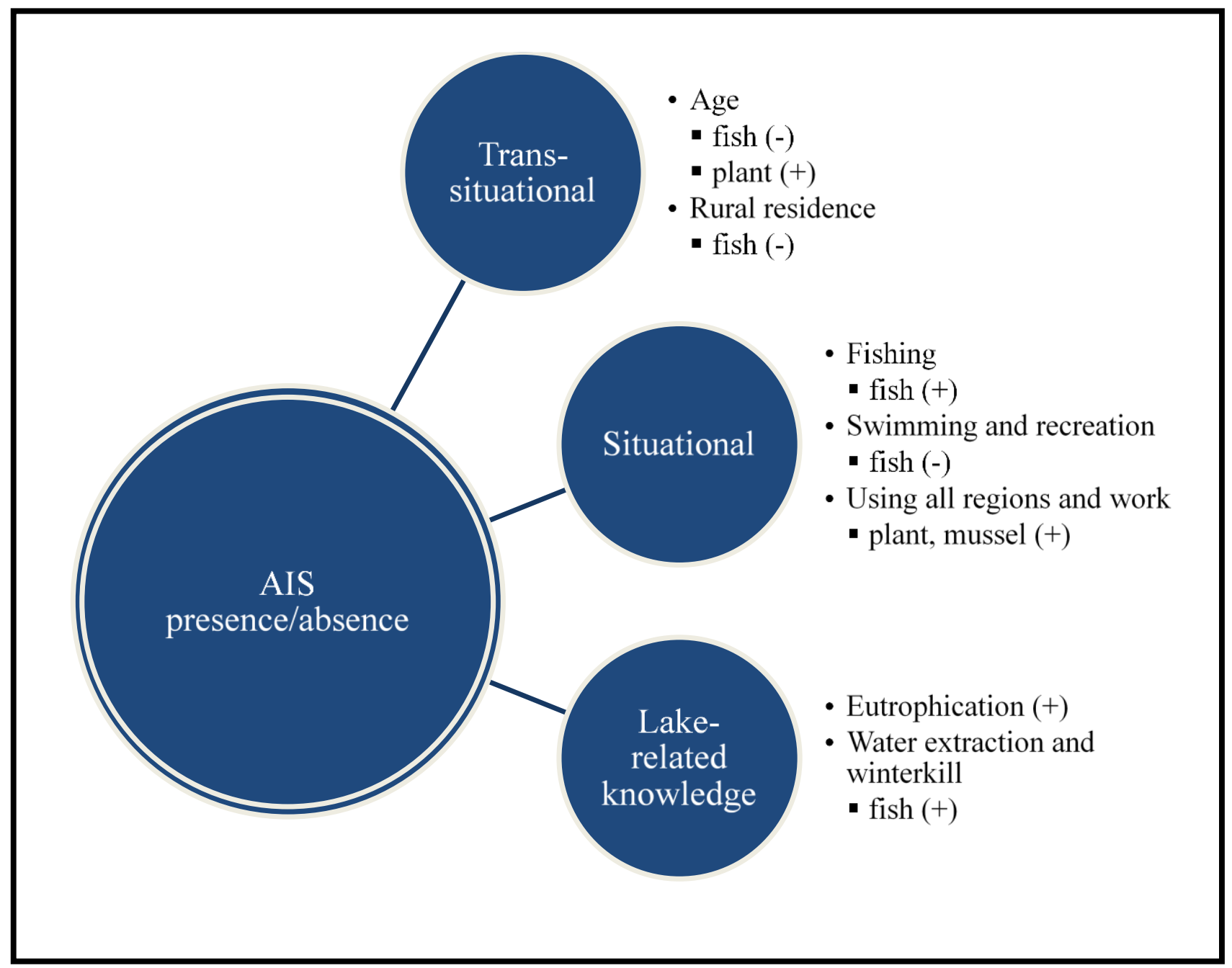

Note. Unless otherwise specified, the predictor impacts all three groups (fish, pant, mussel) of organisms. $(+)$ and (-) indicates the direction of the relationship. For example, older respondents are less knowledgeable about presence of non-native fishes but more knowledgeable about plants. 
Table 4. Stepwise multiple linear regression for predictor variables associated with correctly identifying negative impact of

fish, plant and mussel organisms, PLUMS 2015-2016

\begin{tabular}{|c|c|c|c|c|c|c|c|c|c|c|c|c|}
\hline & \multicolumn{11}{|c|}{ Correctly identifying negative impact of: } & \\
\hline & \multicolumn{4}{|c|}{ Fish Organisms } & \multicolumn{4}{|c|}{ Plant Organisms } & \multicolumn{4}{|c|}{ Mussels Organisms } \\
\hline & B & Beta & Sig. & $\begin{array}{c}\text { Model } \\
\text { Entry } \\
\end{array}$ & $\mathbf{B}$ & Beta & Sig. & \begin{tabular}{|l} 
Model \\
Entry \\
\end{tabular} & B & Beta & Sig. & $\begin{array}{c}\text { Model } \\
\text { Entry } \\
\end{array}$ \\
\hline (Constant) & 0.540 & & 0.090 & & 0.138 & & 0.579 & & 0.493 & & 0.005 & \\
\hline Age & -0.013 & -0.156 & 0.002 & 3 & - & - & - & - & - & - & - & - \\
\hline Male $^{1}$ & 0.441 & 0.160 & 0.002 & 4 & - & - & - & - & 0.373 & 0.197 & 0.000 & 1 \\
\hline \multicolumn{13}{|l|}{ Lakes' Region $^{2}$} \\
\hline South of Diefenbaker Qu'Appelle & - & - & - & - & - & - & - & - & - & - & - & - \\
\hline North of Diefenbaker Qu'Appelle & - & - & - & - & - & - & - & - & - & - & - & - \\
\hline Two different lake regions were used & - & - & - & - & - & - & - & - & - & - & - & - \\
\hline All three lake regions were used & - & - & - & - & - & - & - & - & 0.309 & 0.147 & 0.003 & 3 \\
\hline $\mathbf{R}$ & \multicolumn{4}{|c|}{0.399} & \multicolumn{4}{|c|}{0.319} & \multicolumn{4}{|c|}{0.388} \\
\hline R square & \multicolumn{4}{|c|}{0.159} & \multicolumn{4}{|c|}{0.102} & \multicolumn{4}{|c|}{0.151} \\
\hline
\end{tabular}

Note.${ }^{1}$ Reference category $=$ Female $;{ }^{2}$ Reference category = Diefenbaker - Qu'Appelle system; $(-)=$ Predictor variable did not enter the model. In each model, we entered the following predictors: respondent's sex, age, race, highest educational level, self-perceived SES, city/town/RM of residence, lake's region, purpose: fishing, purpose: swimming, purpose: boating, purpose: recreation, purpose: work, purpose: cabining, awareness of eutrophication, awareness of winterkill and awareness of water extraction. Dummy coded variables (no. of categories -1) were created for categorical predictors. 
Figure 4. Findings-based layout of the impact of trans-situational, situational, and lakerelated knowledge predictors on negative impact of AIS

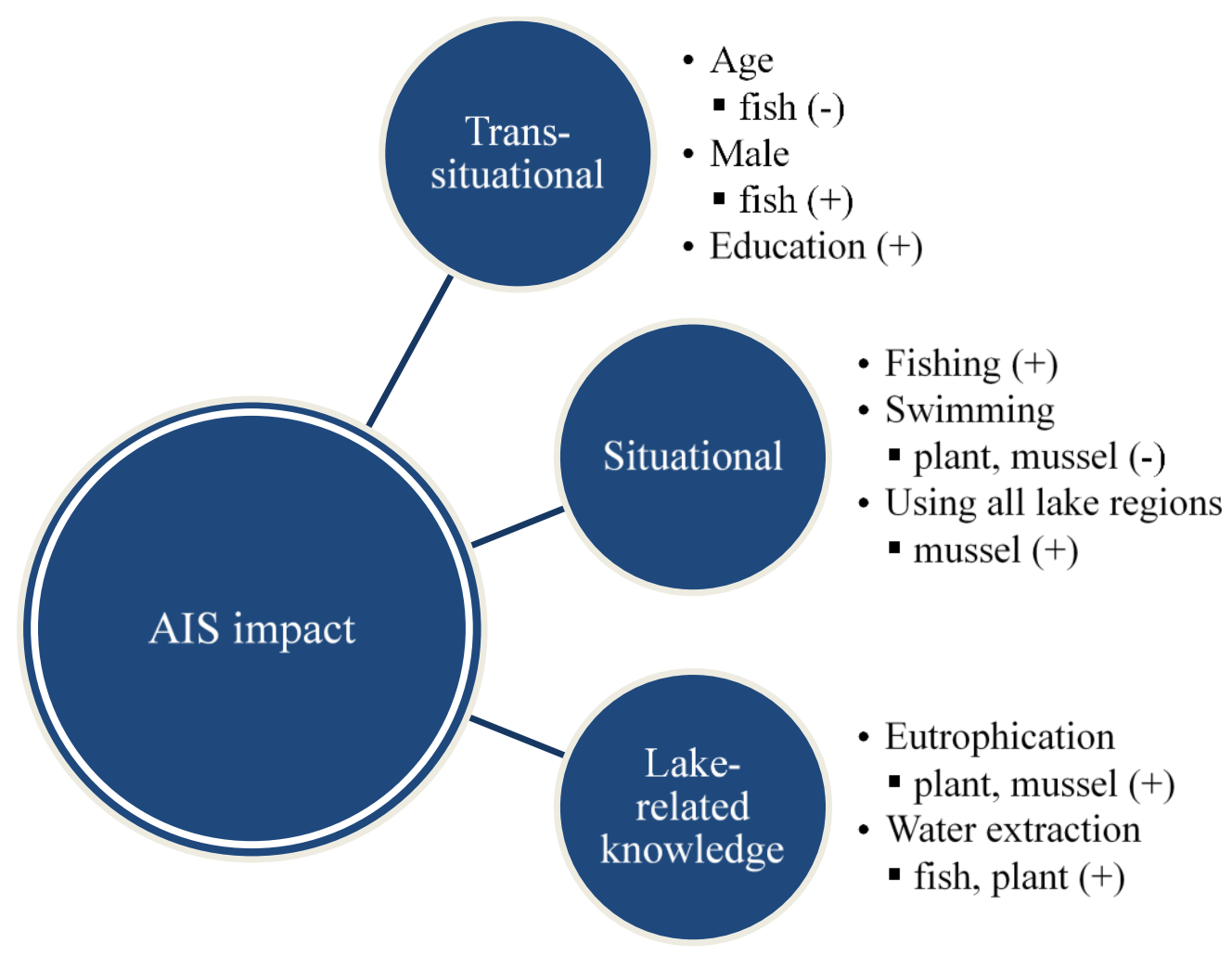

Note. Unless otherwise specified, the predictor impacts all three groups (fish, pant, mussel) of organisms. $(+)$ and (-) indicates the direction of the relationship. For example, older respondents are less knowledgeable about the impact of non-native fishes. 
Table 5. Forward conditional stepwise logistic regression of awareness of zebra and quagga mussels, PLUMS 2015-2016

\begin{tabular}{|c|c|c|c|c|c|c|c|c|}
\hline & \multicolumn{8}{|c|}{ Have you heard about: } \\
\hline & \multicolumn{4}{|c|}{ Zebra Mussels } & \multicolumn{4}{|c|}{ Quagga Mussels } \\
\hline & $\mathbf{B}$ & Sig. & $\operatorname{Exp}(B)$ & $\begin{array}{c}\text { Model } \\
\text { Entry }\end{array}$ & B & Sig. & $\operatorname{Exp}(B)$ & $\begin{array}{c}\text { Model } \\
\text { Entry }\end{array}$ \\
\hline (Constant) & -2.259 & 0.012 & 0.104 & & -1.057 & 0.000 & 0.347 & \\
\hline Age & 0.025 & 0.039 & 1.025 & 5 & - & - & - & - \\
\hline Male $^{1}$ & 1.804 & 0.000 & 6.074 & 1 & - & - & - & - \\
\hline Highest Level of Education & 0.465 & 0.001 & 1.591 & 2 & - & - & - & - \\
\hline Purpose: Swimming & -0.909 & 0.052 & 0.403 & 6 & - & - & - & - \\
\hline Purpose: Work & - & - & - & - & 1.649 & 0.000 & 5.201 & 1 \\
\hline Purpose: Cabining & - & - & - & - & -0.495 & 0.051 & 0.610 & 3 \\
\hline Awareness of Eutrophication & 1.417 & 0.009 & 4.124 & 4 & 0.982 & 0.000 & 2.670 & 2 \\
\hline Awareness of Winterkill & 0.690 & 0.086 & 1.993 & 3 & - & - & - & - \\
\hline -2 Log likelihood & \multicolumn{4}{|c|}{214.860} & \multicolumn{4}{|c|}{409.776} \\
\hline Nagelkerke R Square & \multicolumn{4}{|c|}{0.329} & \multicolumn{4}{|c|}{0.168} \\
\hline
\end{tabular}

Note. ${ }^{1}$ Reference category = Female; $(-)=$ Predictor variable did not enter the model. In each model, we entered the following predictors: respondent's sex, age, race, highest educational level, self-perceived SES, city/town/RM of residence, lake's region, purpose: fishing, purpose: swimming, purpose: boating, purpose: recreation, purpose: work, purpose: cabining, awareness of eutrophication, awareness of winterkill and awareness of water extraction. Dummy coded variables (no. of categories -1) were created for categorical predictors. 
APPENDIX

TABLES 1-5 


\section{Appendix 1. Operational definitions and explanations of concepts in 'invasive species', PLUMS 2015-2016}

\section{Concept and Explanation}

\section{Species}

- List of eight invasive species.

- Three fishes*: common carp (Cyprinus carpio), goldfish (Carassius auratus), and koi (domesticated ornamental varieties of Cyprinus carpio).

- Three plants*: flowering rush (Butomus umbellatus), salt cedar (Tamarix ramosissima, Tamarix chinensis, Tamarix parviflora), and purple loosestrife (Lythrum salicaria).

- Two mussels: zebra mussels (Dreissena polymorpha), and quagga mussels (Dreissena bugensis).

\section{Presence/Absence}

- All fish and plant organisms present, and mussels absent in Saskatchewan at the time surveys were administered.

- Assessed using “yes/no/don’t know” answers to inquiry about awareness of presence/absence of organism.

\section{Impact}

- Organisms listed in the survey have negative impacts on invaded aquatic ecosystems.

- Assessed using "positive/negative/don't know" answers to inquiry about impact of organisms. Increased water clarity due to mussel presence is an example of a positive impact while decreased biodiversity and habitat loss are examples of negative impacts.

\section{Mussels}

- Zebra and quagga mussels are particularly destructive invasive species with far reaching consequences on invaded habitats and regional economies. Therefore, success/failure of government outreach efforts to increase public knowledge of mussels was assessed using yes/no answers to inquiry about awareness of two mussels.

\section{Open-ended Questions}

- How to clean a contaminated boat, inquired about procedure to clean a boat contaminated with zebra or quagga mussels.

- Who to contact, inquired about who should be contacted if mussels are discovered on boat.

Note. * List of organisms was provided by the Saskatchewan Ministry of Environment. 


\section{Appendix 2. Operational definitions of predictor variables considered in the regression analyses, PLUMS 2015-2016}

\section{Variable Label and Explanation}

\section{Socio-Demographic Factors}

- Sex, a discrete, nominal variable. Female is the reference category.

- Age, a continuous, interval/ratio variable that inquired about age at time of survey.

- Residence, self-reported variable that indicates town/city/rural municipality of residence at time of survey. Medium-to-large population center - population of 30,000 or more is the reference category.

- Race, a discrete, nominal variable (White vs. Others). Other is the reference category.

- Level of Education, self-reported variable that indicates highest level of education at time of survey.

- Socio-economic status (SES), reported as self-perceived value on a five-point Likert scale item (1 = "low SES" and 5 = "high SES").

\section{Situational/Contextual Factors}

- Geographic region, three, separate questions that inquired about lake-use in each of all three regions. These were combined into one variable, containing the following responses: A_Diefenbaker - Qu'Appelle system; B_South Diefenbaker QuAppelle; C_North Diefenbaker QuAppelle; Two different lake regions were used; and All three lake regions were used. Diefenbaker - Qu'Appelle system is the reference category.

- Lake-use purpose, seven, separate "yes/no" items that inquired about purposes of lakeuse by geographic region.

\section{Knowledge Factors}

- Eutrophication (“yes/no"), refers to increased algal production due to increased nutrient inputs from watershed.

- Winterkill ("yes/no"), refers to increased fish mortality over winter due to increased biological oxygen demand (especially in eutrophic lakes).

- Extraction ("yes/no"), refers to extraction of water from lakes for industrial, agricultural and municipal purposes. 
Appendix 3. Frequency and percent of lake-use by region, PLUMS 2015-2016

\begin{tabular}{lcc}
\hline Region & Frequency & Percentage (\%) \\
\hline None & 36 & 7.6 \\
\hline Diefenbaker - Qu'Appelle & 98 & 20.6 \\
\hline $\begin{array}{l}\text { South of Diefenbaker - } \\
\text { Qu'Appelle }\end{array}$ & 64 & 13.4 \\
\hline $\begin{array}{l}\text { North of Diefenbaker - } \\
\text { Qu'Appelle }\end{array}$ & 67 & 14.1 \\
\hline Two lake regions & 129 & 27.1 \\
\hline All three lake regions & 82 & 17.2 \\
\hline TOTAL & $\mathbf{4 7 6}$ & $\mathbf{1 0 0}$ \\
\hline
\end{tabular}


Appendix 4. Profiles for the respondents' lake-use by region, including significant chisquared results for region differences, PLUMS 2015-2016

\begin{tabular}{|c|c|c|c|c|c|c|}
\hline \multirow[b]{2}{*}{ Purpose } & \multicolumn{6}{|c|}{ Lake region } \\
\hline & $\begin{array}{l}\text { Diefenbaker- } \\
\text { Qu'Appelle }\end{array}$ & $\begin{array}{c}\text { South of } \\
\text { Diefenbaker- } \\
\text { Qu'Appelle }\end{array}$ & $\begin{array}{c}\text { North of } \\
\text { Diefenbaker- } \\
\text { Qu'Appelle }\end{array}$ & $\begin{array}{l}\text { Two lake } \\
\text { regions }\end{array}$ & $\begin{array}{l}\text { All three } \\
\text { lake } \\
\text { regions }\end{array}$ & TOTAL \\
\hline Fishing* & $\begin{array}{l}73.5 \% \\
n=72\end{array}$ & $\begin{array}{l}60.9 \% \\
n=39\end{array}$ & $\begin{array}{l}77.6 \% \\
n=52\end{array}$ & $\begin{array}{c}81.4 \% \\
n=105\end{array}$ & $\begin{array}{l}82.9 \% \\
n=68\end{array}$ & $\begin{array}{c}76.4 \% \\
n=336\end{array}$ \\
\hline Swimming & $\begin{array}{l}72.4 \% \\
n=71\end{array}$ & $\begin{array}{l}75.0 \% \\
n=48\end{array}$ & $\begin{array}{l}65.7 \% \\
n=44\end{array}$ & $\begin{array}{l}68.2 \% \\
n=88\end{array}$ & $\begin{array}{l}70.7 \% \\
n=58\end{array}$ & $\begin{array}{c}70.2 \% \\
n=309\end{array}$ \\
\hline Boating* & $\begin{array}{l}75.5 \% \\
n=74\end{array}$ & $\begin{array}{l}85.9 \% \\
n=55\end{array}$ & $\begin{array}{l}61.2 \% \\
n=41\end{array}$ & $\begin{array}{l}76.0 \% \\
n=98\end{array}$ & $\begin{array}{l}70.7 \% \\
n=58\end{array}$ & $\begin{array}{c}74.1 \% \\
n=326\end{array}$ \\
\hline Recreation & $\begin{array}{l}72.4 \% \\
n=71\end{array}$ & $\begin{array}{l}67.2 \% \\
n=43\end{array}$ & $\begin{array}{l}59.7 \% \\
n=40\end{array}$ & $\begin{array}{l}62.8 \% \\
n=81\end{array}$ & $\begin{array}{l}63.4 \% \\
n=52\end{array}$ & $\begin{array}{c}65.2 \% \\
n=287\end{array}$ \\
\hline Work* & $\begin{array}{l}7.1 \% \\
n=7\end{array}$ & $\begin{array}{l}4.7 \% \\
n=3\end{array}$ & $\begin{array}{l}7.5 \% \\
n=5\end{array}$ & $\begin{array}{l}6.2 \% \\
n=8\end{array}$ & $\begin{array}{l}18.3 \% \\
n=15\end{array}$ & $\begin{array}{c}8.6 \% \\
n=38\end{array}$ \\
\hline Farm $^{+}$ & $\begin{array}{l}3.1 \% \\
n=3\end{array}$ & $\begin{array}{l}1.6 \% \\
n=1\end{array}$ & $\begin{array}{l}0.0 \% \\
n=0\end{array}$ & $\begin{array}{l}1.6 \% \\
n=2\end{array}$ & $\begin{array}{l}1.2 \% \\
n=1\end{array}$ & $\begin{array}{l}1.6 \% \\
n=7\end{array}$ \\
\hline Cabin** & $\begin{array}{l}35.7 \% \\
n=35\end{array}$ & $\begin{array}{l}59.4 \% \\
n=38\end{array}$ & $\begin{array}{l}44.8 \% \\
n=30\end{array}$ & $\begin{array}{l}30.2 \% \\
n=39\end{array}$ & $\begin{array}{l}36.6 \% \\
n=30\end{array}$ & $\begin{array}{c}39.1 \% \\
n=172\end{array}$ \\
\hline
\end{tabular}

Note. Valid percent (\%, first row) and frequency $\left(n\right.$, second row). ${ }^{*} \mathrm{p}<0.05 ; * * \mathrm{p}<0.01 ;{ }^{+}$few cases. 
Appendix 5. Frequency and percent results for awareness of non-native mussels, PLUMS 2015-2016

\begin{tabular}{lcccc}
\hline & \multicolumn{2}{c}{ Yes } & No \\
\cline { 2 - 5 } & Frequency & Percentage (\%) & Frequency & Percentage (\%) \\
$\begin{array}{l}\text { Have you heard } \\
\text { about? }\end{array}$ & 378 & 86.7 & 58 & 13.3 \\
\hline Zebra mussels ${ }^{+}$ & 141 & 32.6 & 291 & 67.4 \\
\hline Quagga mussels ${ }^{++}$ & & & & \\
\hline
\end{tabular}

Note. ${ }^{+} 4$ respondents did not answer; ${ }^{++} 8$ respondents did not answer. 